\title{
Using M-QAM-OFDM in Downstream Link and WBTW-SOA in Upstream of a Bidirectional WDM-PON System
}

\author{
Ayoob Alateeq, Mohammad A. Matin \\ Department Electrical and computer Engineering, University of Denver, Denver, USA \\ Email: Ayoob.alateeq@du.edu
}

Received January 18, 2013; revised February 20, 2013; accepted February 27, 2013

\begin{abstract}
The passive optical network WDM-PON is one of the most dominant performers of all communication systems, and provides sufficient broadband service. Providing enough data for the demands of today and the future, marks this area as a critical topic for researchers. The first goal of this article is to study the performance of OFDM in a bidirectional WDM-PON by using QAM and BPSK modulation methods in the downstream link. The second goal is to build the upstream link with WBTW-SOA and show its ability to transmit the upstream signal with low equipment. Sending and receiving signals from the central office to the last mile, and opposite of the network up to $100 \mathrm{Km}$ via a bidirectional single mode optical fiber (SMF) was successfully achieved.
\end{abstract}

Keywords: PON-WDM; OFDM; QAM; BPSK

\section{Introduction}

Provisioning broadband services for downloading and uploading high definition data has become a difficult requirement for data providers. Covering users' data demand for the future has encouraged many researchers to find suitable ways to develop transmitted or received data. Using a wavelength division multiplexing in passive optical network (WDM-PON) is one of the implementations that have been added to cover this additional demand Figure 1. WDM-PON has shown its ability to increase the bandwidth of the signal, as a result of expanding the bandwidth, the signal capacity will increase [1]. Moreover, transmission data via optical fiber has a limitation of how far distance data can be transmitted, after a certain distance dispersion will occur. Besides using WDM-PON in the communication systems as an enhanced change, orthogonal frequency division multiplexing (OFDM) has been used to encode data in a multicarrier frequency. The carrier signal of an OFDM is the sum of the orthogonal subcarriers, which are individually modulated by different types of modulation such as quadrature amplitude modulation (QAM) or phase-shift keying (PSK). Using M-QAM OFDM in the WDM-PON systems helps to increase multi-accesses of multi-users $[2,3]$. An easy way to provide multi-paths, which are used in most broadband systems between transmitters and receivers, is to use OFDM. In order for WDM-PON

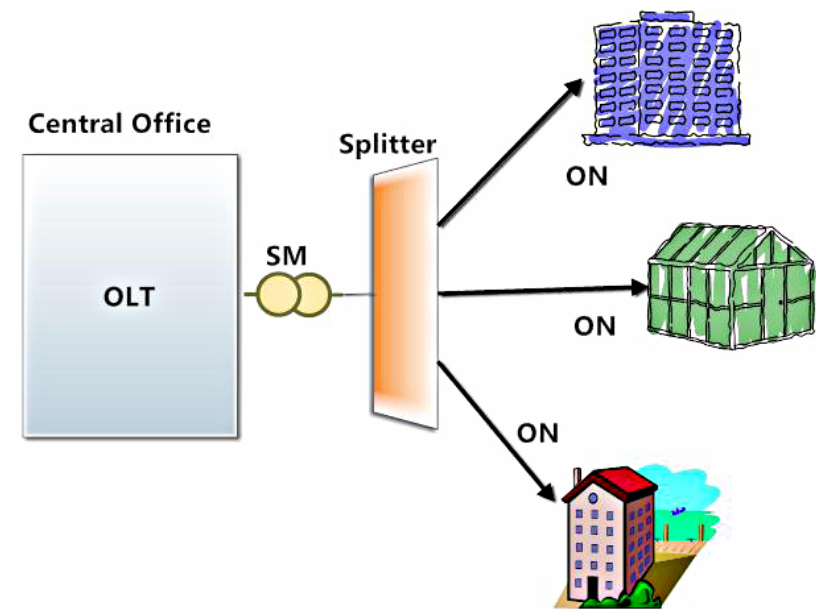

Figure 1. Simple architecture of PON WDM.

to provide multi-paths between the transmission and reception terminals, M-QAM OFDM must be used. Using QAM, which offers orthogonal modulation, helps to modulate each subcarrier independently [4]. In this paper, we have proposed an OFDM bidirectional WDM-PON design that is modulated by several types of QAM for the downstream, and uses a wideband traveling wave semiconductor optical amplifier WBTW-SOA for the upstream. We have compared several types of OFDM modulations such as BPSK, 16-QAM, and 64-QAM for the same WDM-PON system. We also tried to expand the 
transmission length up to $100 \mathrm{Km}$ and study the constellation and SNR of downstream and BER and Q factor of upstream.

\section{Design Configuration}

\subsection{Downstream Design}

Figure 2 contains four identical channels that are multiplexed by a wavelength division multiplexer. For the downlink design, in each channels OFDM is used. Modulation of OFDM in this design has been tried by using BPSK 16-QAM and 64-QAM. Each one of the two ports of OFDM goes through low pass filter LP which has a cutoff frequency equaling $7.44 \mathrm{GHz}$. The filtered signals will be modulated with CW lasers by using mach zehnder modulators (MZM). The output laser signals of MZM will be multiplexed by using WDM and sent via bidirectional single mode optical fiber (SMF). The optical fiber length in this design has been varied from 40 to $100 \mathrm{Km}$. Before and after the optical fiber, multiplexed signal in the downlink will pass through two EDFAs with gains equal to $13 \mathrm{~dB}$ and $12 \mathrm{~dB}$ respectively. After the second EDFA an optical circulator is used to redirect the signals of downlink and uplink. At the receiver side, and after the circulator, DWDM is used to separate the received signal into four signals for each channel. Each signal has been detected by a photodiode detector, which converts the optical signal to an electro signal. This electrical signal will be demodulated by using an OFDM demodulator and a QAM sequence decoder [1-3,5-10].

\subsection{Upload Design}

For the uplink, the wideband travelling wave semiconductor optical amplifier (WBTW-SOA) is used to simu- late the traveling wave SOA that is based on an identical hidden edge SOA. A transmitter source Tx and CW laser source are coupled by using an optical coupler and the output is applied to WBTW-SOA. The output signal of WBTW-SOA will be sent via the uplink of SMF. Before reaching the $\mathrm{PD}$ at the receiver side, EDFA is used to amplify the signal. SMF in this link has been varied, and the bit error is compared.

\section{Result and Discussion}

We simulate the design by using the Optiwave software $\mathrm{V}-11$ to analyze and discuss the results. For the downstream link, we tried three different types of OFDM modulation; we used BPSK, 16 QAM, and 64-QAM. For each type, the SMF length varied from 60, 80 and 100 $\mathrm{Km}$. At a certain length of SMF, we found that maximum received power occurs when 64-QAM OFDM is used. However, the minimum received power occurs when BPSK is used as shown in Figure 3. To study the quality of the received signals, which is modulated and demodulated by using QAM, an electrical constellation visualizer is used. Modulation of the digital OFDM signal by using 2-QAM or BPSK was our first step in this experiment. Figure 4 shows a constellation diagram of three different cases of BPSK, when SMF equals 60, 80 and $100 \mathrm{Km}$, respectively. A $60 \mathrm{Km}$ length of SMF can be clearly seen, the constellation is more clearly arranged, and the stars are separated (Figure 4(a)). Expanding the SMF length up to 80 and $100 \mathrm{Km}$ (Figures 4(b) and (c)) respectively, gives us constellations that are less arranged than the constellation at $60 \mathrm{~km}$. Having scattered constellations in 80 and $100 \mathrm{~km}$ shows that the qualities of the received signals are less than at $60 \mathrm{~km}$, however, these qualities are acceptable overall.

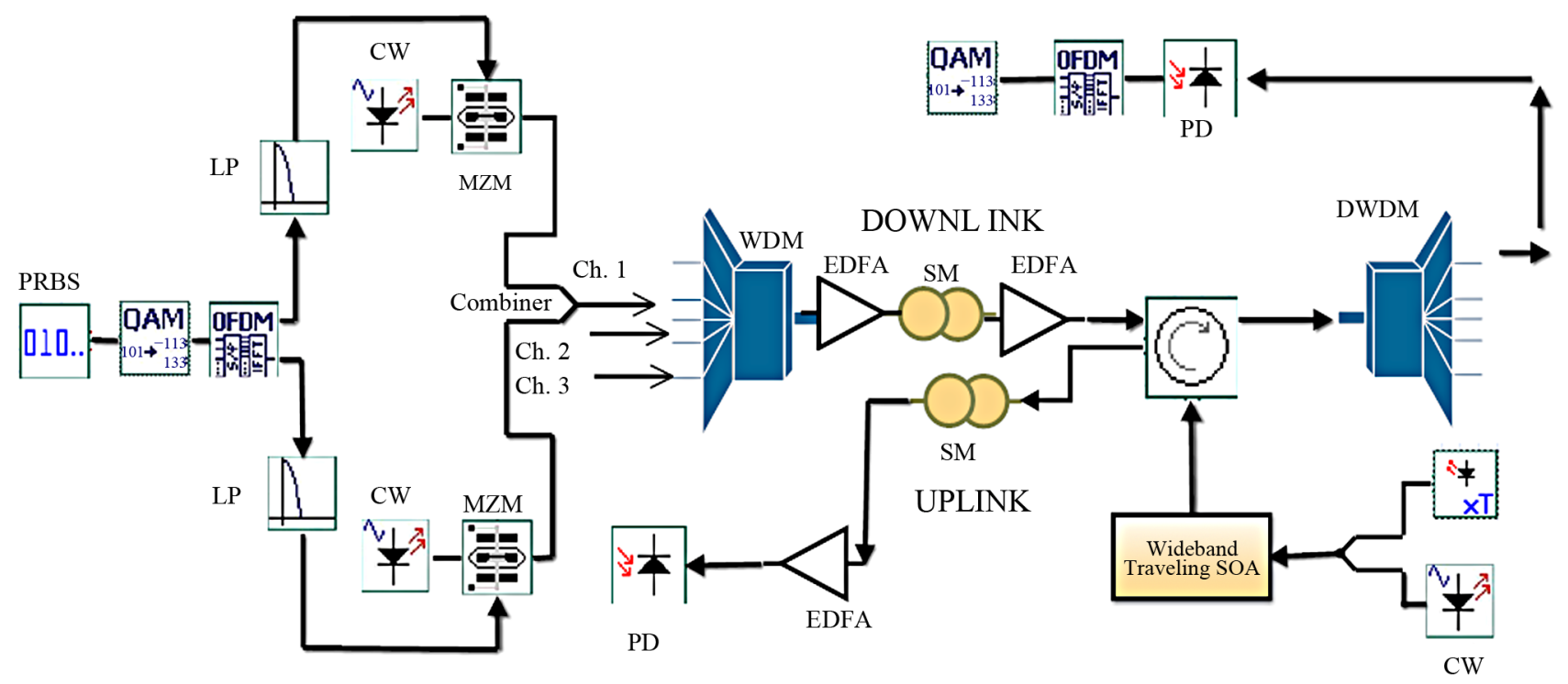

Figure 2. Proposed bidirectional WDM-PON system with OFDM downstream link and WBTW-ROS for Upstream link. 
Figure 5 represents a constellation diagram where a 16-QAM modulation is used at a different length of SM. When a $60 \mathrm{~km}$ SMF is used, the received signals show a more clearly arranged constellation (Figure 5(a)), as compared to the constellations when 80 and $100 \mathrm{~km} \mathrm{SMF}$ is used. Using a 64-QAM modulation type produces more power than the other types. However, the constellations of the received signals are more scattered, espe- cially at $100 \mathrm{~km}$ (Figure 6). The upstream link BER and $\mathrm{Q}$ factor were measured at different lengths of SMF. When $60 \mathrm{Km}$ SMF is used, the BER equals 37.8, and the $\mathrm{Q}$ factor is very close to zero. Having less BER and more $\mathrm{Q}$ factor portrays a large eye opening in the eye diagram pattern (Figure 7(a)). As the SMF length expanded, the BER increases, and the $\mathrm{Q}$ factor reduces; as a result the opening eye will became smaller (Figures 7(b) and (c)).

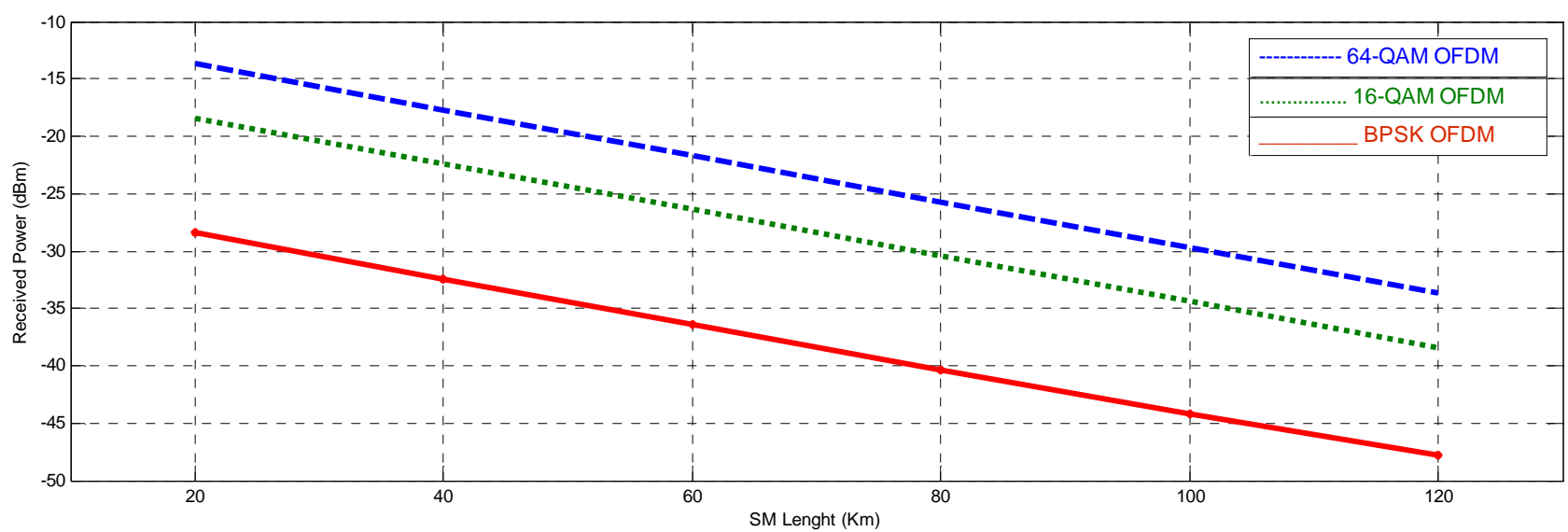

Figure 3. Received power of downlink signal vs length of SMF.

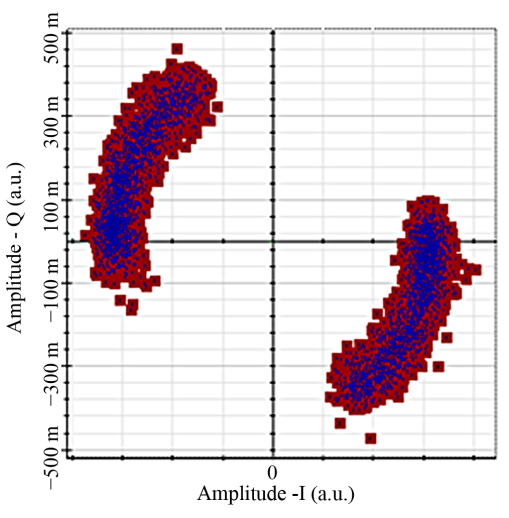

(a)

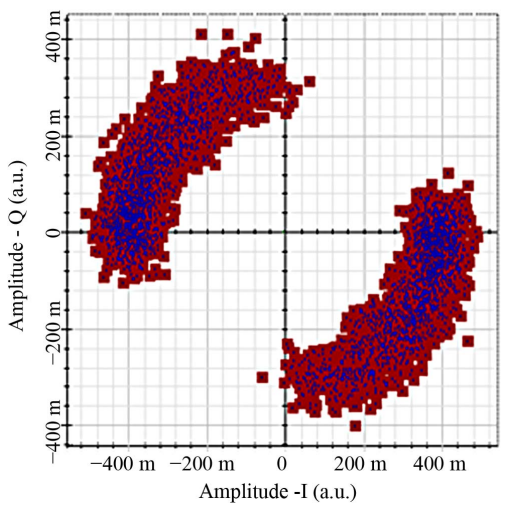

(b)

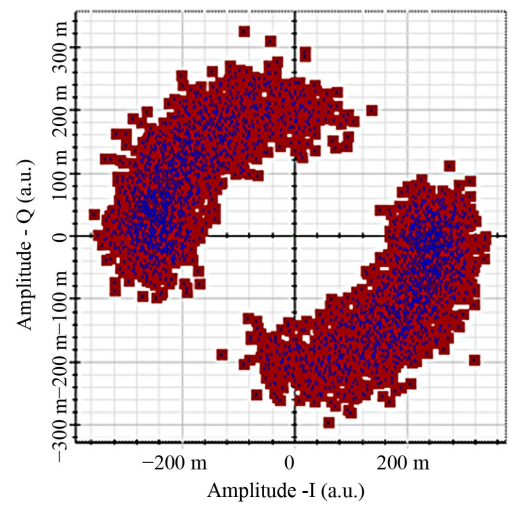

(c)

Figure 4. Electrical constellation of the received downlink signal modulated by BPSK over (a) $60 \mathrm{Km}$ (b) $80 \mathrm{Km}$ (c) $100 \mathrm{Km}$.

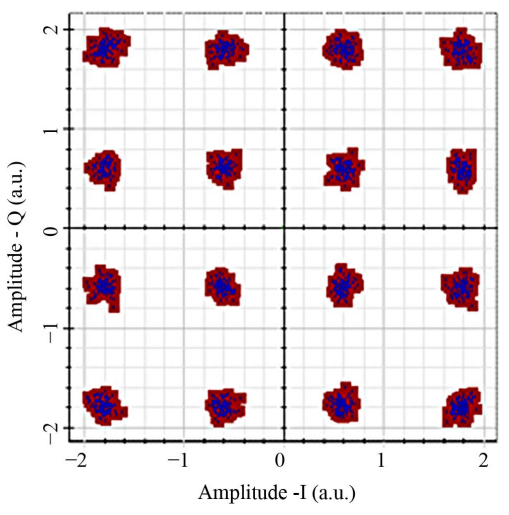

(a)

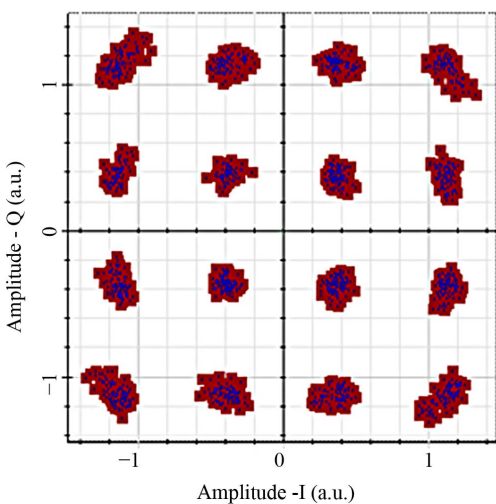

(b)

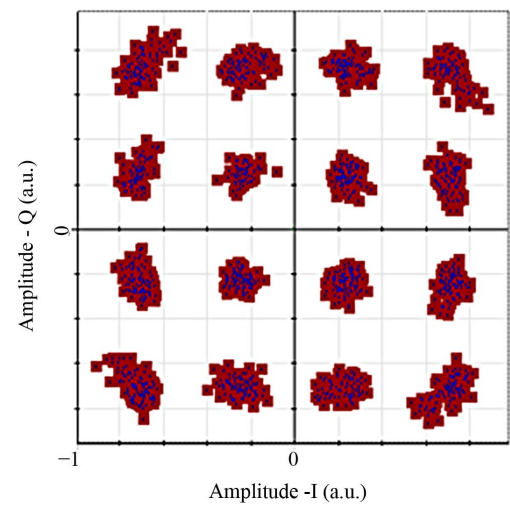

(c)

Figure 5. Electrical constellation of the received downlink signal modulated by 16 QAM over (a) $60 \mathrm{Km}$ (b) $80 \mathrm{Km}$ (c) $100 \mathrm{Km}$. 


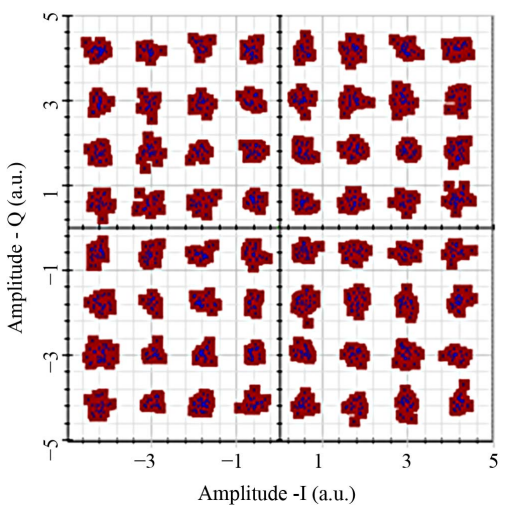

(a)

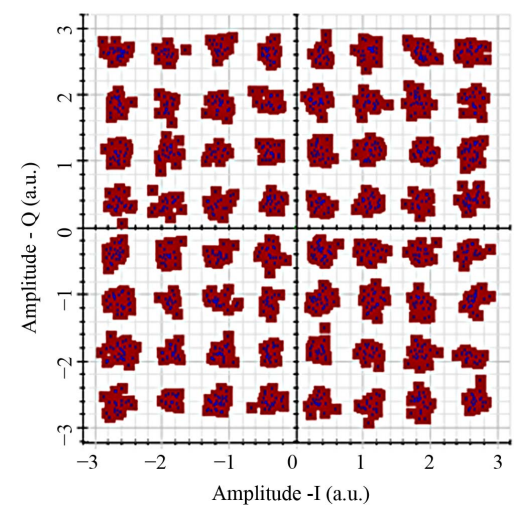

(b)

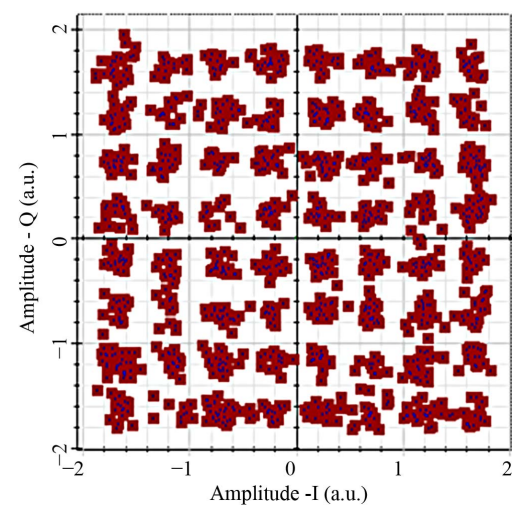

(c)

Figure 6. Electrical constellation of the received downlink signal modulated by 64 QAM over (a) $60 \mathrm{Km}$ (b) $80 \mathrm{Km}$ (c) $100 \mathrm{Km}$.

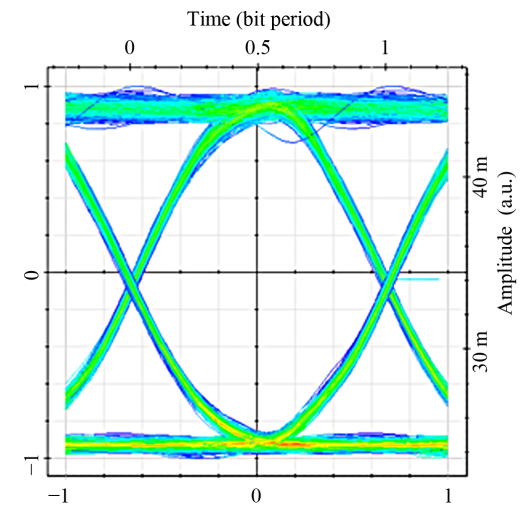

(a)

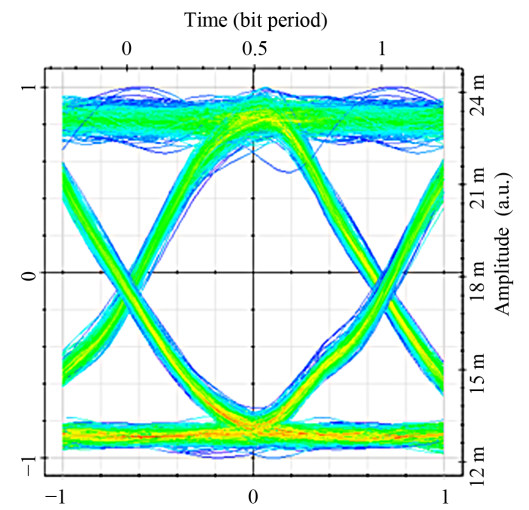

(b)

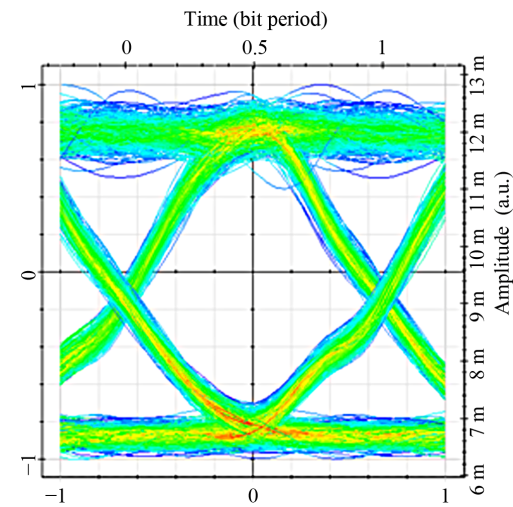

(c)

Figure 7. Eye diagram of the received uplink signal with different length of SMF (a) $60 \mathrm{~km}$ (b) $80 \mathrm{Km}$ (c) $100 \mathrm{Km}$.

\section{Conclusion}

In this paper we have demonstrated how to transmit signals via SMF with lengths up to $100 \mathrm{~km}$ by using OFDM, which is modulated by BPSK, 16QAM, and 64QAM in the downstream link. The received signals were studied by using an electrical constellation visualizer, which helps to show the constellation of the symbols at the receiver's end. According to the maximum received power when 64-QAM was used, the best modulation method is 64-QAM, while BPSK is the worst. For the upstream link, the wide band traveling wave modulator was used, and the BER and Q factor of the received signals were measured. Even when expanding the SMF length up to 100 $\mathrm{km}$, the opening eye of the received signals is big enough for having received signals with good qualities.

\section{REFERENCES}

[1] S. Chi, C. Yeh and C. Chow, "Broadband Access Technology for Passive Optical Network,” Broadband Access Communication Technology III, Vol. 7234, 2009, Article ID: 723408 .

[2] M. Hu, S. Wu, M. Fang and L. Tang, “A Wavelength
Reuse OFDM-WDM-PON Architecture with Downstream OFDM and Upstream OOK Modulations,” IEEE 3rd International Conference on Communication Software and Networks (ICCSN), Xi'an, 27-29 May 2011, pp. 389-392.

[3] A. Alateeq, K. Alatawi, F. Almasoudi and M. A. Matin, "Design of Broadband RoF PON for the Last Mile," Scientific and Research: Journal of Communications and Network, Vol. 4, 2012, pp. 269-277.

[4] L. Hanzo, S. X. Ng, T. Keller and W. T. Webb, “Quadrature Amplitude Modulation: From Basics to Adaptive Trellis-Coded, Turbo-Equalised and Space-Time Coded OFDM, CDMA and MC-CDMA Systems,” 2nd Edition, Wiley, John \& Sons, Incorporated, Hoboken, 2004, pp. 397-480

[5] N. Nowshin, A. Arifuzzman and M. Tarique, "Demonstration and Performance Analysis of RoF Based OFDMPON System for Next-Genaration Faber Optic Communication,” International Journal of Computer Networks \& Communications, Vol. 4, No. 1, 2012, pp. 193-209.

[6] B. Liu, L. Zhang, X. Xin and J. Yu, "ConstellationMasked Secure Communication Technique for OFDMPON,” Optics Express, Vol. 20, No. 22, 2012, pp. 2516125168.

[7] C. Chow, C. Yeh, C. Wang, F. Shih, C. Pan and S. Chi, "WDM Extended Reach Passive Optical Networks Using 
OFDM-QAM,” Optics Express, Vol. 16, No. 16, 2008, pp. 12096-12101. doi:10.1364/OE.16.012096

[8] X. Hu, L. Zhang, P. Cao, K. Wang and Y. Su, "Energy-Efficient WDM-OFDM-PON Employing Shared OFDM Modulation Modules in Optical Line Terminal," Optics Express, Vol. 20, No. 7, 2012, pp. 8071-8077.

[9] J. Huang, D. Liu and C. Zeng, “10 Gb/s WDM-PON Us- ing Downstream OFDM and Upstream OOK,” Computer and Information Science, Vol. 4, No. 2, 2011, pp. 34-38.

[10] B. liu, L. Zhang, X. Xin and J. Yu, "Symmetric Terabit WDM Pre-DFT OFDM Access Network Using PCFSupercontinuum,” Optics Express, Vol. 20, No. 22, 2012, pp. 24356-24363. 